
\title{
BReserch S Suare \\ Radiation Induced Silver Nanoparticles in Ionically Crosslinked Alginate Beads for Efficient Catalytic Degradation of Basic Dye
}

Manal F. abou Taleb ( $\square$ abutalib_m@yahoo.com )

Egyptian Atomic Energy Authority https://orcid.org/0000-0003-1674-5157

Faten Ismail Abou El Fadl

Egyptian Atomic Energy Authority

Hanan Albalwi

Egyptian Atomic Energy Authority

Mohamed M. Ibrahim

Taif University

\section{Research Article}

Keywords: Alginates, Silver Nanoparticles, catalytic degradation

Posted Date: March 22nd, 2021

DOI: https://doi.org/10.21203/rs.3.rs-332011/v1

License: (c) (i) This work is licensed under a Creative Commons Attribution 4.0 International License.

Read Full License 


\title{
Radiation induced silver nanoparticles in ionically crosslinked Alginate beads for efficient catalytic degradation of basic dye
}

\author{
Manal F. Abou Taleb ${ }^{1,2 *}$, Faten Ismail Abou El Fadl ${ }^{2}$, Hanan Albalwi ${ }^{1}$, Mohamed \\ M. Ibrahim ${ }^{3}$
}

${ }^{1}$ Department of Chemistry, College of Science and Humanities in Al-Kharj, Prince Sattam Bin Abdulaziz University, Al-kharj 11942, Saudi Arabia

${ }^{2}$ Polymer chemistry department, National Center for Radiation Research and Technology (NCRRT), Egyptian Atomic Energy Authority, Nasr City, P.O. Box 7551, Cairo 11762, Egypt.

${ }^{3}$ Department of Chemistry, College of Science, Taif University, P.O. Box 11099, Taif 21944, Saudi Arabia.

* Corresponding author at: Department of Chemistry, College of Science and Humanities in AlKharj, Prince Sattam Bin Abdulaziz University, Al-kharj 11942, Saudi Arabia

E-mail addresses: abutalib_m@yahoo.com,m.aboutaleb@psau.edu.sa

https://orcid.org/my-orcid, https://www.linkedin.com/

\section{Running Head}

Catalytic degradation of sandocryl dye using Ca-ALG /Ag nanocomposite

\begin{abstract}
Silver nanoparticles (Ag NPs) are widely used as engineered nanomaterials in many advanced nanotechnologies, due to their versatile, easy and cheap preparations combined with peculiar chemical-physical properties. Their increased production and integration in environmental applications including water treatment raise concerns for their impact on humans and the environment. In this study, gamma radiation dose of $20 \mathrm{kGy}$ was utilized to induce the synthesis silver nanoparticles (Ag NPs) in the alginate micro beads to prepare calcium Alginate/Ag (CaALG/Ag) nanocomposite beads. These beads were then used to degrade toxic basic dyes in waste water. Initially, Ca-ALG /Ag nanocomposite beads were synthesized and characterized using Ultra Violet-visible spectrum (UV-Vis), Scanning Electron Microscope (SEM), X-Ray Diffraction (XRD) and Transmission Electron Microscope (TEM) for confirming the formation of Ag NPs and morphological study. The catalytic efficiency of the resulting Ca-ALG/Ag nanocomposite beads is evaluated for the degradation of dyes such sandocryl blue dye in the presence of $\mathrm{NaBH}_{4}$. The catalytic degradation of sandocryl blue dye was very fast in the present conditions: $0.1 \mathrm{~g}$ of
\end{abstract}


catalyst $5 \mathrm{ml} \mathrm{NaBH}_{4}$ and the optimum time for complete reduction was $30 \mathrm{~min}$. The pseudo-first order, pseudo second order and intra particle diffusion model used to evaluate the kinetic models and the mechanism of the degradation. Results showed that the degradation kinetics best fit the pseudo-second-order model and Langmuir isotherm model. The Biopolymer-based nanocomposite beads of calcium alginate, and Ag NPs can be applied to reduce dyestuff, where it is economically viable and environmentally friendly.

Keywords: Alginates, Silver Nanoparticles; catalytic degradation

\section{Introduction}

In recent years, nanotechnology and its uses are among the most excited research fields with application in many industrial parts. This is due to their unique physicochemical properties and another advantages such that they can be more specific and highly sensitive material for their selective applications [1]. Indeed, their applications have been applied in many technology areas, for instance, antimicrobial [2], and waste water treatment[3].

Engineered nanomaterials (ENMs) are typically defined as materials smaller than $100 \mathrm{~nm}$ in at least one dimension, and they have specific surface functionalizations and size-dependent properties, such as high reactivity and large surface-to-volume ratio, that satisfy their wide range of applications, including in sensing, optics energy, catalysis, biotechnology and so on[4].

Synthesized metal nanoparticles are carried out by various chemical, physical, and biological methods, such as pyrolysis [5], chemical vapor deposition and sol-gel [6]; that is, most of them use toxic reagent and are expensive. Therefore, high efforts in the synthesis of noble metal nanoparticles using environmentally friendly methods are required. These solutions generally are produced by the use of gamma radiation especially in preparation of Ag NPs[7].

Radiation synthesized silver nanoparticles incorporated with biodegradable sodium alginate lead to the formation of alginate micro beads[8]. The synthesis of alginate beads occurs through ionotropic gelation methods which are found to be simple and time-consuming. The incorporation of metal nanoparticles into the porous structures improves the physical and chemical nature of the nanocomposite hydrogel toward a variety of applications[9].

Since the end of the last century, a variety of wastes from chemical and pharmaceutical industries have been released into the environment through wastewater streams. These effluents mainly consist of surfactants, disinfectants, detergents, and personal care products. One of the major forms of pollutants is dye wastes and has become a major environmental threat drawing 
concerns globally[10]. Currently, most of the dye wastes are being treated using physical and chemical treatment methods but they fail to remove dyes completely considering that they are not degradable in nature [11]. Therefore, it is necessary to take sustainable initiatives that use principles from safe methods and tools to remove the dyes before releasing into the aquatic system. For ages, catalysis has been one of the most common techniques used for the degradation of organic dyes into nontoxic substances in wastewater[12][6][13].

Based on previous concepts and facts, this work focused on the clean preparation of silver nanoparticles (Ag NPs) within a biocompatible and environmentally friendly polymer alginate taking the advance of the ionotropic gelation of alginate to form micro beads. The prepared calcium alginate/Ag nanocomposite beads were fully characterized and examined as a highly efficient catalyst for fast degradation of basic dye.

\section{Experimental}

\subsection{Materials}

Sodium alginate (SA), was purchased from Sigma-Aldrich. Calcium chloride dihydrate $\left(\mathrm{CaCl}_{2} .2 \mathrm{H}_{2} \mathrm{O}\right)$ was purchased from Algomhoria Co. Egypt. Silver nitrate $\mathrm{AgNO}_{3}$ and sodium borohydride were purchased from Acros. Doubly distilled water was used throughout the study. All reagents were of analytical grade or better and were used as received without further purification.

\subsection{Preparation of calcium Alginate (Ca-ALG) beads}

The preparation of sodium alginate beads by ionic crosslinking was followed as reported in literature with some modifications [14]. Sodium alginate (SA) stock solution was prepared by dissolving five grams of alginate powder in beaker and stirring with magnetic stirrer over night to give homogeneous viscous solution $(5 \% \mathrm{wt} / \mathrm{v})$. By using a $10 \mathrm{ml}$ syringe the SA was transferred drop wisely into a solution of $\mathrm{CaCl}_{2} .2 \mathrm{H}_{2} \mathrm{O}(3 \% \mathrm{wt} / \mathrm{v})$ with continuous stirring. Hydrogel beads were formed instantly; then they were left in contact with the solution for $30 \mathrm{~min}$ in order to complete the gelation process. Finally, the resulting beads were rinsed gently with distilled water and dried at $37{ }^{\circ} \mathrm{C}$ for further work.

\subsection{Radiation preparation of calcium-Alginate/Ag (Ca-ALG/Ag) nanocomposite beads}

Certain amount of the calcium alginate beads prepared in the previous step was taken and soaked in a beaker containing $30 \mathrm{ml}$ of silver nitrate solution (1M). The beaker were covered 
carefully with aluminum foil and left for $24 \mathrm{~h}$ for complete loading of Ag ions in alginate beads and then exposed to $20 \mathrm{kGy}$ gamma radiations to enhance the reduction of silver ions to silver nanoparticles. The formed Ca-Alginate/Ag nanocomposite beads were then removed and washed thoroughly using stainless steel grid with distilled water and left to dry at room temperature for further steps.

\subsection{Catalytic degradation of basic dye}

The degradation of basic dye carried out at room temperature. In this study, a volume of $40 \mathrm{ml}$ of the aqueous solution of basic dye with the concentration of $1000 \mathrm{mg} / \mathrm{L}$ was introduced in a beaker containing $0.1 \mathrm{~g}$ of Ca-ALG/Ag nanocomposite beads as a catalyst, and then the mixture was stirred for $30 \mathrm{~min}$, after which $5 \mathrm{ml}$ of $\mathrm{NaBH}_{4}(0.5 \mathrm{M})$ was added and the absorbance of the dye solution was monitored using UV-Vis spectroscope over the 300-700 $\mathrm{nm}$ range to measure basic dye solution absorbance samples at 5 min interval during catalytic reduction. The reaction mixture was stirred vigorously using magnetic stirrer for during the entire reaction time. Samples were collected at appreciate intervals and were centrifuged to remove catalyst particles with high-speed centrifugal. After short definite intervals of time, an aliquot of the solution was transferred to a quartz cuvette and its UV-Vis absorbance spectrum was recorded at the specific wavelength of the dye used. The extent of dye degradation was calculated using the relation:

$$
\text { Degradation } \%=\frac{A_{o}-A_{t}}{A_{o}} \times 100
$$

Where $A_{o}$ is the initial absorbance of dye solution and $A_{t}$ is the absorbance at different time intervals.

For the effect of dosage of catalyst various amounts of Ca-ALG/Ag nanocomposite beads $(0.1$, $0.15,0.2 \mathrm{~g}$ ) on the degradation $\%$ was used.

The effect of reducing agent content $\left(\mathrm{NaBH}_{4}\right)$ on the degradation $\%$ was also, studied by varying the volume $(3,4,5 \mathrm{ml})$ with respect to the total volume of dye sample $(40 \mathrm{ml})$. Figure 1 illustrates the photographic preparation and dye degradation by Ca-ALG/Ag nanocomposite beads 


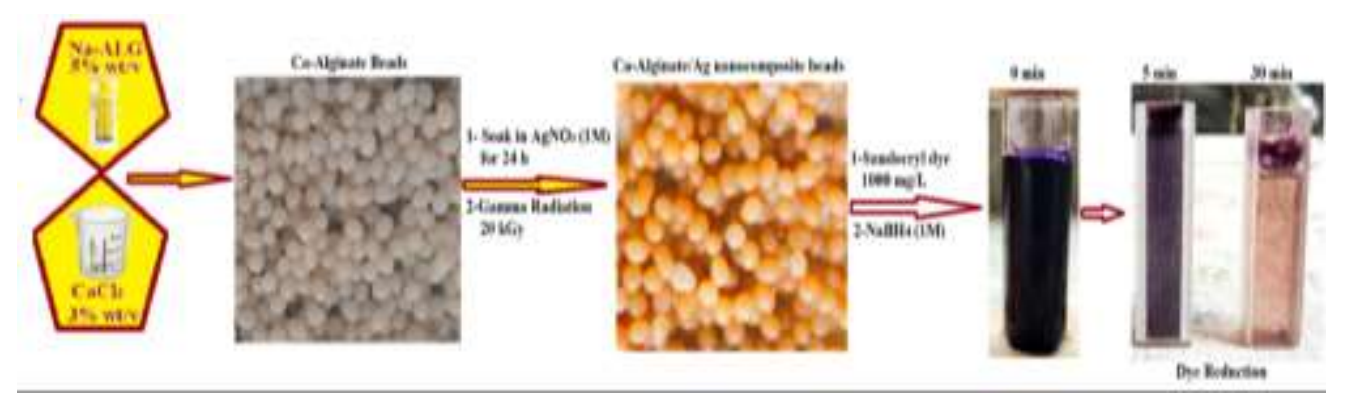

Figure 1: photographic illustration for the preparation and degradation of sandocryl dye using CaALG/Ag nanocomposite beads

\section{Kinetic studies}

pseudo-first-order kinetics for adsorption/degradation process of dyes applied using equation 3 [15]:

$$
\text { Pseudo - first - order model: } \ln \left(q_{e}-q_{t}\right)=\ln q_{e}-k_{1} t
$$

Where $q_{\mathrm{e}}$ and $q_{\mathrm{t}}\left(\mathrm{mg} \mathrm{g}^{-1}\right)$ are the amount of dye degraded at equilibrium and time $\mathrm{t}(\mathrm{min})$, respectively, and $k_{1}$ is the rate constant $\left(\mathrm{min}^{-1}\right)$.

For pseudo-second-order kinetics, linear form applied as in equation 3:

$$
\text { Pseudo - second - order model: } \frac{t}{q_{t}}=\frac{1}{k_{2} q e^{2}}+\frac{t}{q_{e}}
$$

$\mathrm{k}_{2}(\mathrm{~g} / \mathrm{mg} \mathrm{min})$ is the equilibrium rate constant. The values of $\mathrm{q}_{\mathrm{e}}$ and $\mathrm{k}_{2}$ are inferred from the plot of $\left(\mathrm{t} / \mathrm{q}_{\mathrm{t}}\right)$ versus $\mathrm{t}$.

\section{Isothermal fitting of data}

Equilibrium isotherm equations are used to describe experimental sorption data.

Freundlich isotherm model obtained by the linear form of the Freundlich expression (4):

$$
\ln q_{e}=\ln K_{f}+\frac{1}{n} \ln C_{e}
$$

Where $\mathrm{q}_{\mathrm{e}}$ is the amount of dye adsorbed at equilibrium time $(\mathrm{mg} / \mathrm{g})$, Ce is equilibrium concentration dye in solution $(\mathrm{mg} / \mathrm{L}), \mathrm{K}_{\mathrm{F}}$ the Freundlich constant $(\mathrm{L} / \mathrm{g})$ related to the bonding energy and $1 / \mathrm{n}_{\mathrm{F}}$ is the heterogeneity factor. The values of $1 / \mathrm{n}_{\mathrm{F}}$ and $\mathrm{K}_{\mathrm{F}}$ are obtained from the slope and intercept of plots $\operatorname{lnq}_{\mathrm{e}}$ versus $\ln \mathrm{C}_{\mathrm{e}}$, respectively.

Langmuir isotherm linearized model form is given by Equation (5):

$$
\frac{c_{e}}{q_{e}}=\frac{1}{q_{m}} b+\frac{1}{q_{m}} C_{e}
$$


Where, $\mathrm{C}_{\mathrm{e}}(\mathrm{mg} / \mathrm{L})$ and $\mathrm{q}_{\mathrm{e}}(\mathrm{mg} / \mathrm{g})$ are the liquid phase and solid phase concentrations of dye at equilibrium. $\mathrm{q}_{\mathrm{m}}$ is the constant related to the single layer adsorption/degradation capacity, and $\mathrm{b}$ is a constant for degradation energy.

\section{5. characterizations}

Fourier transform infrared (FT-IR) spectroscopy was measured between $4000-400 \mathrm{~cm}^{-1}$, using a Nicolet IS-10 FTIR spectrophotometer. X-ray diffraction (XRD) analyses were performed on a Shimadzu machine (XD-DI Series) with $\mathrm{Cu}-\mathrm{K} \alpha$ radiation $(\lambda=1.54 \AA$ ), operated at $40 \mathrm{kV}$ and $30 \mathrm{~mA}$. XRD patterns were recorded in the range of $2 \theta=4-90^{\circ}$. Transmission electron microscopy (TEM) was carried out on JEOL JEM-100CX, Japan. To image the magnetic nanoparticles on the TEM, finely ground beads samples were dispersed in $1 \mathrm{ml}$ of ethanol and then they sonicated to get a solution of magnetic nanoparticles. Approximately 10-20 $\mu$ of this solution was dropped onto a $3 \mathrm{~mm}$ copper grid, which was then dried at room temperature. The surface morphology of different beads was taken with a JSM5400 instrument by JEOL-Japan. A sputter coater was used to pre-coat conductive gold onto the surface before observing the microstructure at $10 \mathrm{kV}$. A UV/VIS spectrometer recording the spectra over the 300-700 $\mathrm{nm}$ range was used to measure acid dye solution samples at 30min interval during oxidation degradation.

\section{Results and Discussions}

\subsection{Characterization of Ca-ALG/Ag nanocomposite beads}

\subsubsection{IR spectroscopy}

In the FTIR spectrum of calcium alginate/Ag beads is shown in Figure 2 all the characteristic bands of Ca-ALG are presented in the figure where a broad band at $3365.9 \mathrm{~cm}^{-1}$ is corresponded to $-\mathrm{OH}$ stretching vibration of calcium alginate, and the bands at 2959 and $2736 \mathrm{~cm}^{-1}$ belong to symmetric and asymmetric $\mathrm{C}-\mathrm{H}$ stretching, respectively are obviously presented. The bands which appeared at 1605 and $1402 \mathrm{~cm}^{-1}$ are assigned to asymmetric and symmetric stretching vibrations of carboxyl groups of calcium alginate, respectively. The band at $1155 \mathrm{~cm}^{-1}$ attributes to $\mathrm{C}-\mathrm{O}-\mathrm{C}$ group. The diminishing of some bands of $\mathrm{Ca}-\mathrm{ALg} / \mathrm{Ag}$ spectrum was relative to $\mathrm{Ag}+$ particles expand adsorption. 


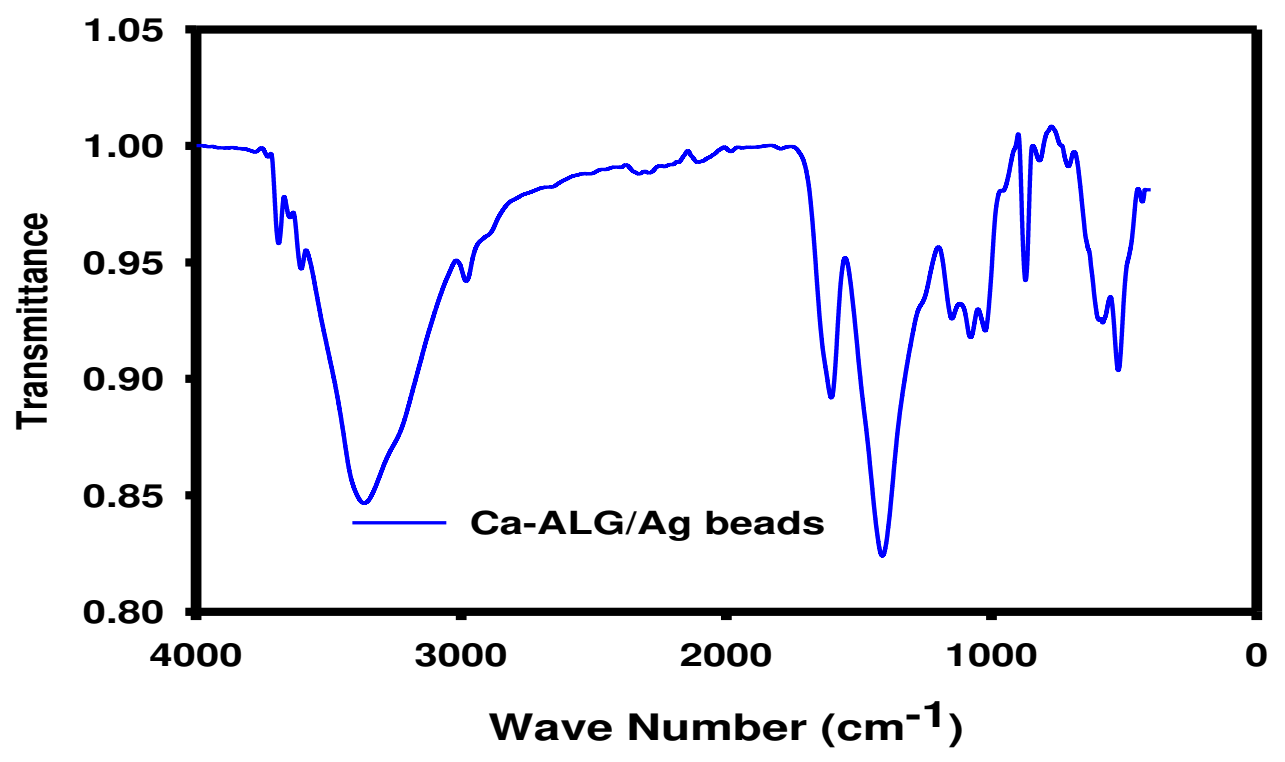

Figure 2: IR spectra of Ca-ALG/Ag nanocomposite beads

\subsubsection{Scanning Electron Microscope (SEM)}

Figure 3 shows the SEM photos of the fracture surface of Ca-Alginate beads and Ca-ALG/Ag nanocomposite beads. It is clear from the SEM micrographs the change occurred on the calcium alginate bead after incorporation of Ag NPs by the effect of radiation where the shape of beads transformed from fixed oval shape to unfixed shape full of very fine particles that related to $\mathrm{Ag}$ NPs causing noticeable increase in surface roughness.
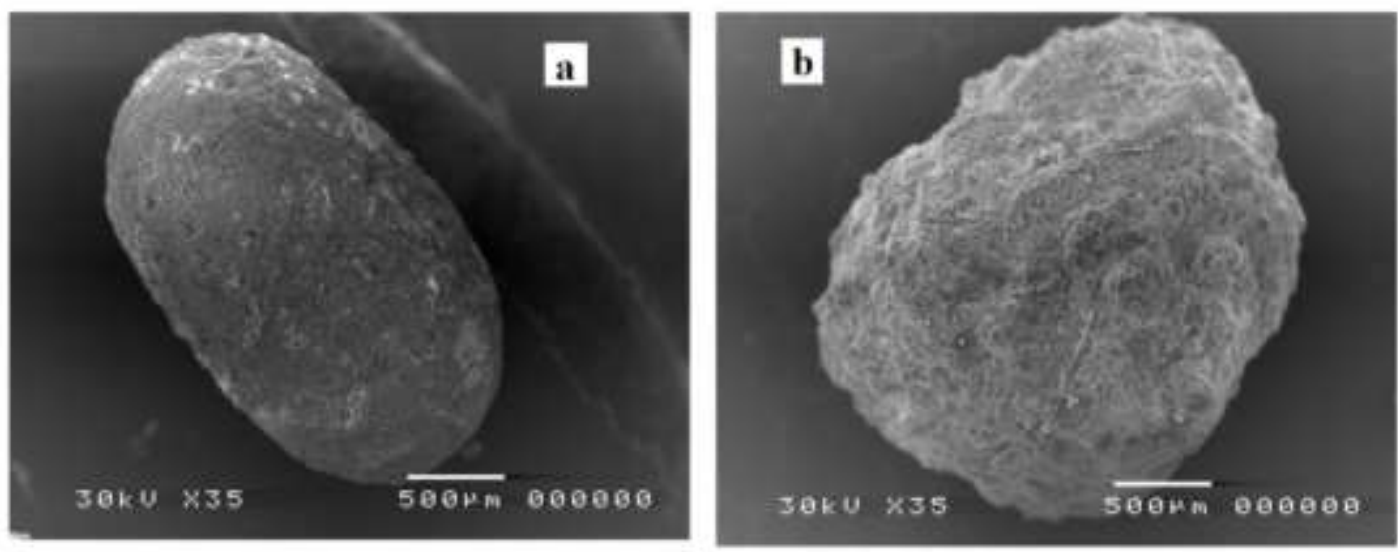
Figure 3: SEM photos of a) Ca-Alginate beads and Ca-ALG/Ag nanocomposite beads

\subsubsection{X-ray diffraction}

XRD patterns of pure Ag NPs and Ca-ALG/Ag nanocomposite beads are illustrated in Figure 4. Five peaks at $2 \theta$ values of $31.56,35.3,46.4,60.6$, and 68.5385 degrees corresponding to (111), (200), (220), (311) and (222) planes of Silver is observed and compared with the standard powder diffraction card of Joint Committee on Powder Diffraction Standards (JCPDS), silver file No. 040783[16]. Examining the XRD of Ca-ALG/Ag nanocomposite beads confirms the presence of the main characteristic peaks of Ag NPs that induced in the alginate beads matrix by gamma radiation[17]. It is noticed from Figure 4 the change in the base line of the XRD pattern of CaALG/Ag nanocomposite beads sample due to the effect of polymer network.

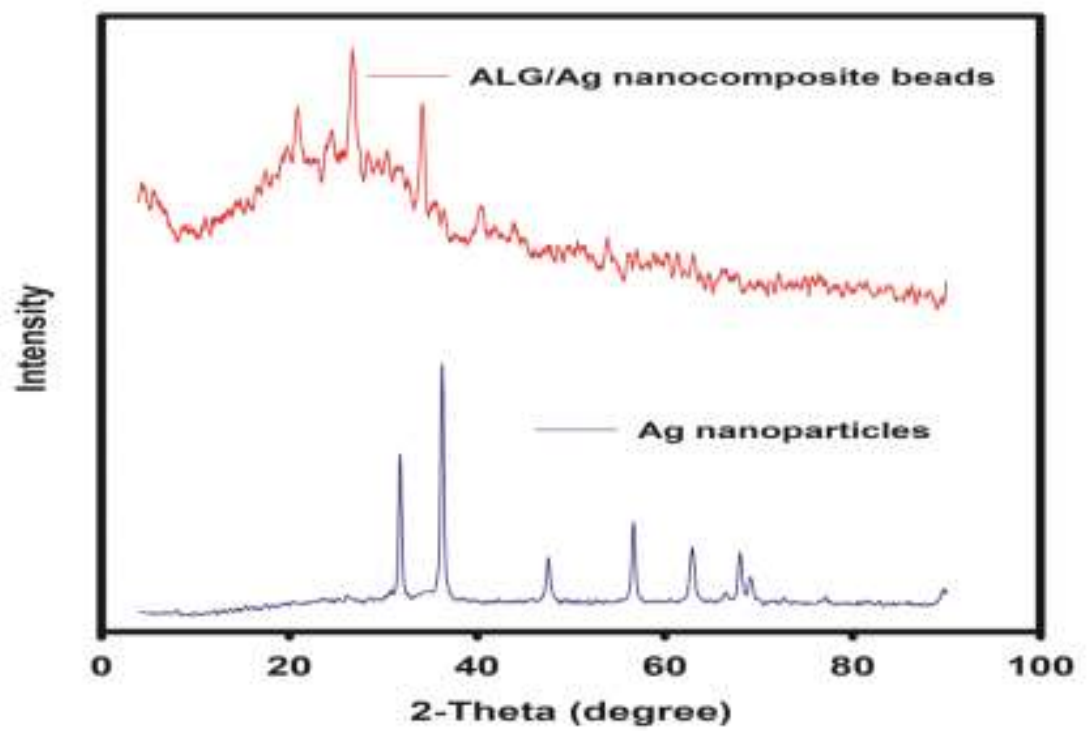

Figure 4: XRD patterns of pure Ag NPs, and Ca-ALG/Ag nanocomposite beads

\subsubsection{Transmission Electron Microscope (TEM)}

TEM technique is used for the morphological evaluation of nanoparticles and in addition estimation of particle size[18]. Figure 5 represents the TEM image of the Ag NPs incorporated in the Ca-alginate beads by gamma radiation. It is cleared from Figure 5 the formation of similar particles nearly equal in size which estimated to be $15.5 \mathrm{~nm}$. 


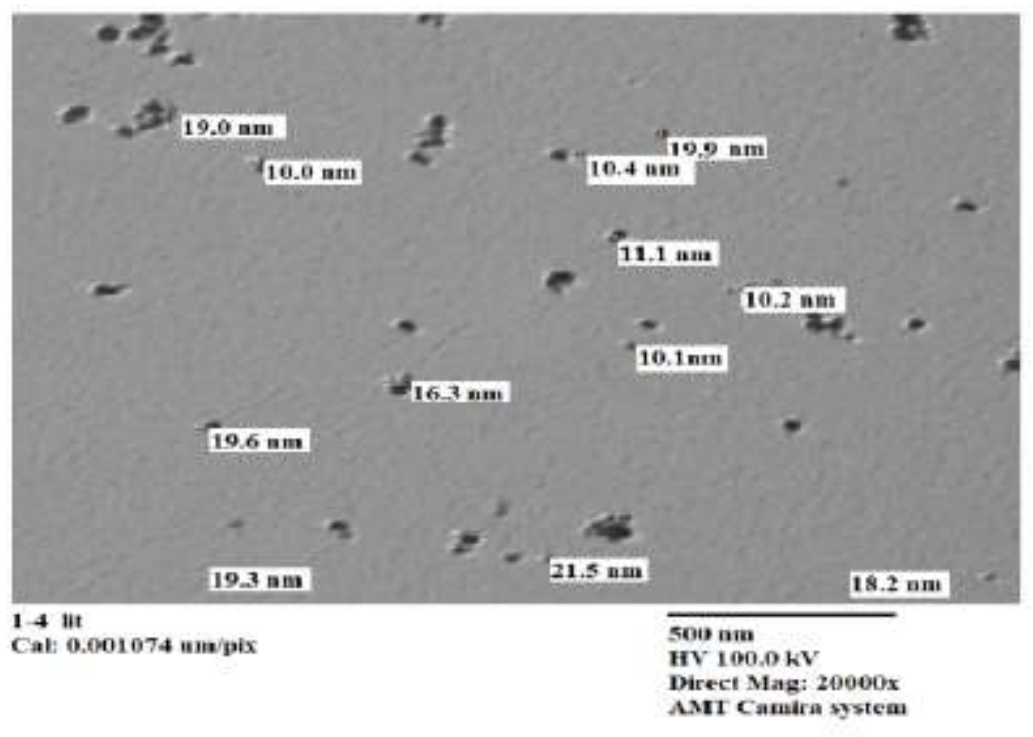

Figure 5: TEM images of Ca-ALG/Ag nanocomposite beads

\subsection{Catalytic degradation of basic dye}

Heterogeneous catalytic degradation processes comprise several steps, such as physical or chemical adsorption, chemical reactions occurring between the species formed at the catalyst surface followed by degradation and reaction products formation (such as halides, metals, inorganic acids, organic compounds), and adsorption/desorption of these products. Therefore, the description of heterogeneous catalysis with specific adsorption modelling tools also involves the consideration of secondary chemical processes (pseudo-adsorption), to which is added the influence of substrate morphology, especially in the inter-particle diffusion stage[19].

Basic dye (sandocryl dye) was selected as a model pollutant to investigate the catalytic ability of the Ca-ALG/Ag nano-catalyst beads with $\mathrm{NaBH}_{4}$ as the reducing agent. $\mathrm{NaBH}_{4}$ was used intensively in the literatures as the reducing agent because of high electron injection capability of the $\mathrm{BH}^{-4}$ ions. It was seen that addition of Ca-ALG /Ag nano-catalyst beads and $\mathrm{NaBH}_{4}$ rapidly weakened the blue color of dye solution to a colorless one after only $30 \mathrm{~min}$. The sandocryl dye absorption peak intensity at $644 \mathrm{~nm}$ decreased with time. The time-dependent UV-Vis spectra screening the reduction outline of sandocryl dye by $\mathrm{NaBH}_{4}$ over Ca-ALG/Ag nano-catalyst beads is presented in Figure 6. As can be seen from the figure, the absorption intensity became zero after $35 \mathrm{~min}$, indicating the completion of the degradation reaction. Hence, it could be concluded that the nanocomposite beads efficiently catalyzed the reduction of basic dye by relaying of electrons 
from $\mathrm{BH}^{-4}$ species to Sandocryl via the Ag NPs, similar work was done by PRANJAL SAIKIA et al, based on using $\mathrm{Au} / \mathrm{CeO}_{2}-\mathrm{TiO}_{2}$ nano-hybrid for fast degradation of methylene blue [20]. Figure 7 shows the effect of time on the absorbance of sandocryl dye during degradation and the degradation \% achieved with time using Ca-ALG/Ag nanocomposite beads as a catalyst.

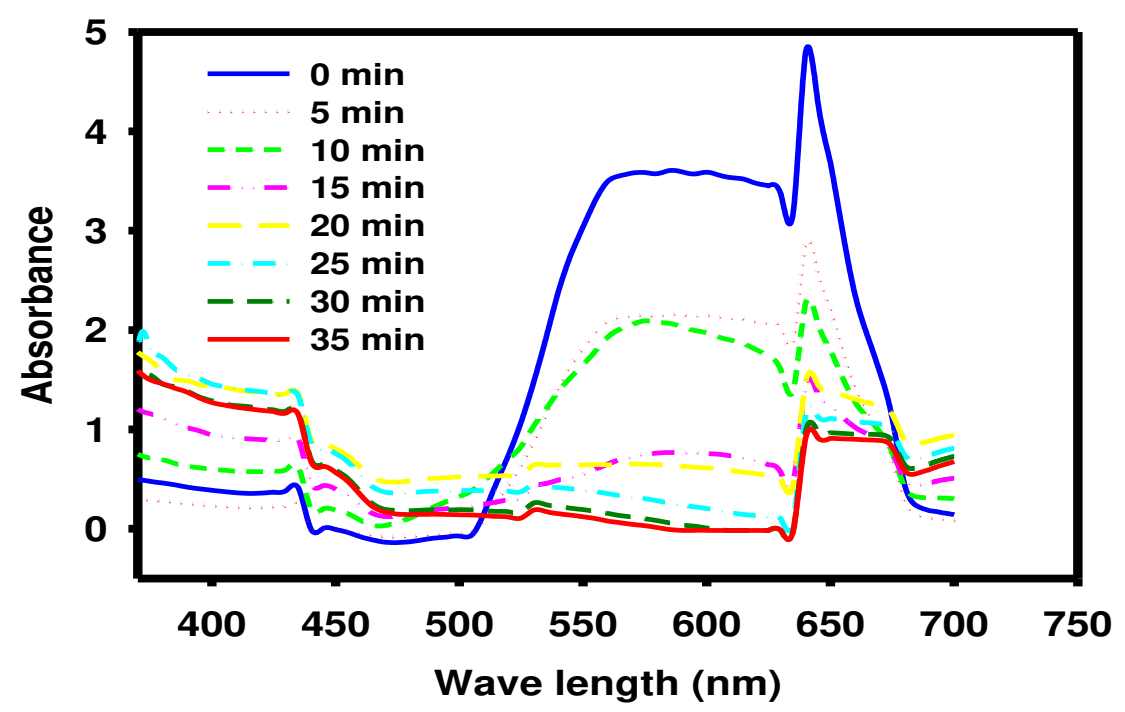

Figure 6: UV-Vis absorption spectra of aqueous sandocryl dye $(40 \mathrm{~mL}, 1000 \mathrm{mg} / \mathrm{L})$ with, $3 \mathrm{~mL}$ of $0.5 \mathrm{M} \mathrm{NaBH}_{4}$ and $0.1 \mathrm{~g}$ of $\mathrm{Ca}-\mathrm{ALG} / \mathrm{Ag}$ nanocomposite beads
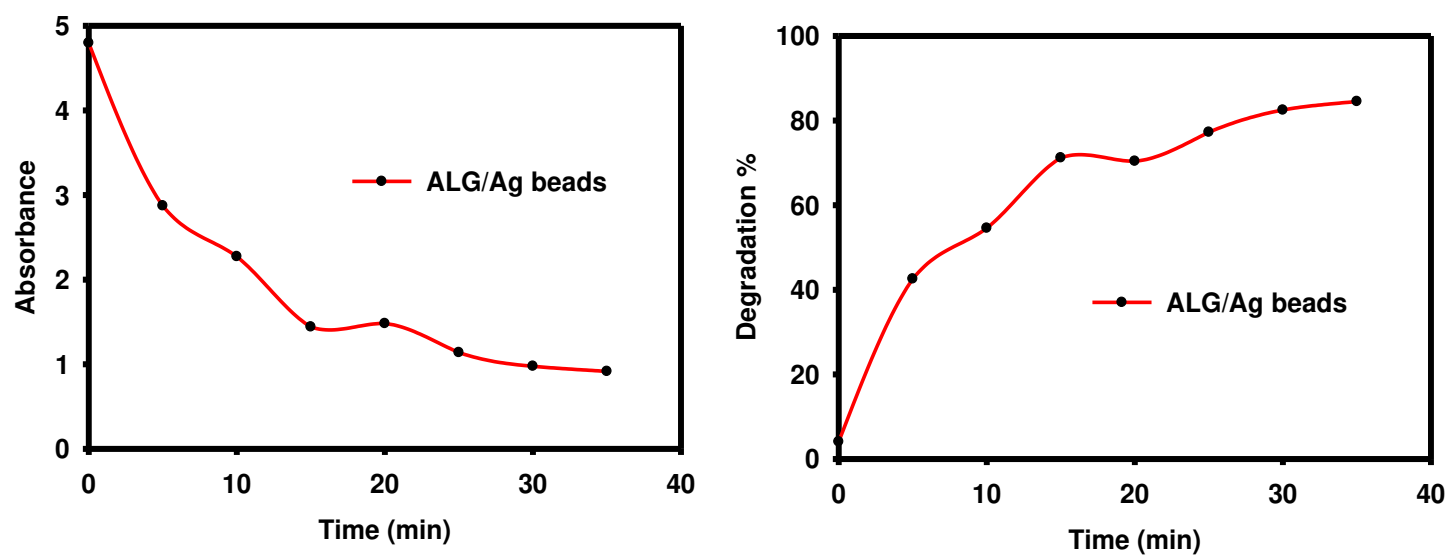

Figure 7: effect of time on the absorbance of sandocryl dye and the degradation \% using CaALG/Ag nanocomposite beads as a catalyst (sample volume $40 \mathrm{ml}$, catalyst dosage $0.1 \mathrm{~g}$, dye concentration $1000 \mathrm{mg} / \mathrm{L}$, and $3 \mathrm{ml}$ of $\mathrm{NaBH}_{4}$ )

\subsubsection{Effect of different parameters on degradation process}


In the case of fast catalytic degradation of dyes it is very important to study the effect of dosage of catalyst and also the content of the reducing agent. Figures 8 and 9 represent the catalytic degradation of sandocryl dye using different amounts of Ca-ALG/Ag nanocomposite beads as a catalyst and various contents of $\mathrm{NaBH}_{4}$ as a reducing agent. It is concluded from these results that the degradation of sandocryl dye is mainly dependent on the catalyst dosage where with increasing the amount of $\mathrm{Ca}-\mathrm{ALG} / \mathrm{Ag}$ nanocomposite beads from 0.1 up to only $0.2 \mathrm{~g}$ the catalytic degradation is completed in shorter time $(25 \mathrm{~min})$. This due to increasing the amount of catalyst results in high intensity of active sites available for faster degradation of dye. While on the other hand increasing the content of $\mathrm{NaBH}_{4}$ from $3 \mathrm{ml}$ to $5 \mathrm{ml}$ has negligible effect on the degradation of sandocryl dye.

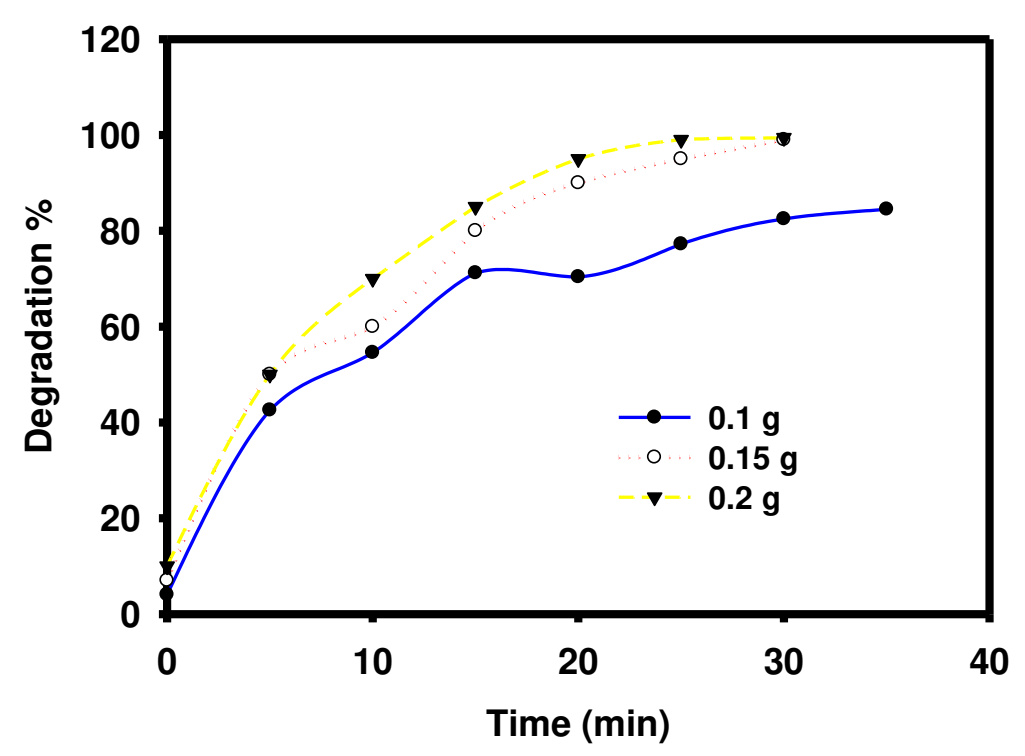

Figure 8: Effect of Ca-ALG/Ag nanocomposite beads dosage on the catalytic degradation of sandocryl dye $\left(\mathrm{NaBH}_{4} 3 \mathrm{ml}\right.$, dye concentration $1000 \mathrm{mg} / \mathrm{L}$, and $40 \mathrm{ml}$ sample volume) 


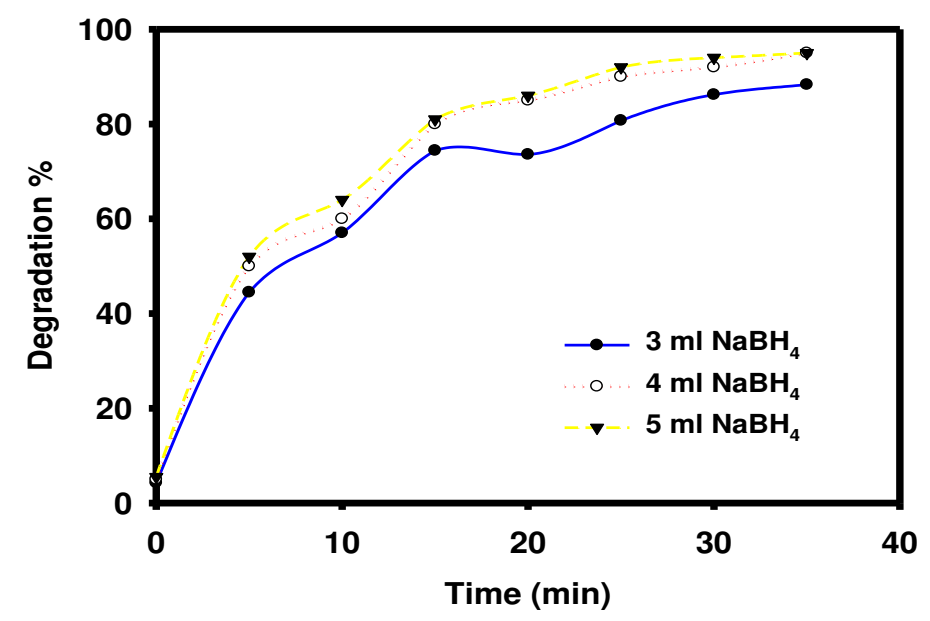

Figure 9: Effect of $\mathrm{NaBH}_{4}$ volume on the catalytic degradation of sandocryl dye (dye concentration $1000 \mathrm{mg} / \mathrm{L}$, and $40 \mathrm{ml}$ sample volume, catalyst dosage $0.15 \mathrm{~g}$ )

\section{Kinetic study}

Study of adsorption degradation kinetics is important because the rate of adsorption or degradation (which is one of the criteria for efficiency of adsorbent) and also the mechanism of adsorption can be concluded from kinetic studies[21]. Figure 10 represents the kinetic models; pseudo-first-order, pseudo-second-order of catalytic degradation of sandocryl dye by Ca-ALG/Ag nanocomposite beads the various parameters related to these models are summarized in Table1. From monitoring the values of $R^{2}$ it is found that the degradation of the sandocryl dye using Ca-ALG/Ag nanocomposite beads in presence of $\mathrm{NaBH}_{4}$ as a reducing agent is best fitted by second order model. 

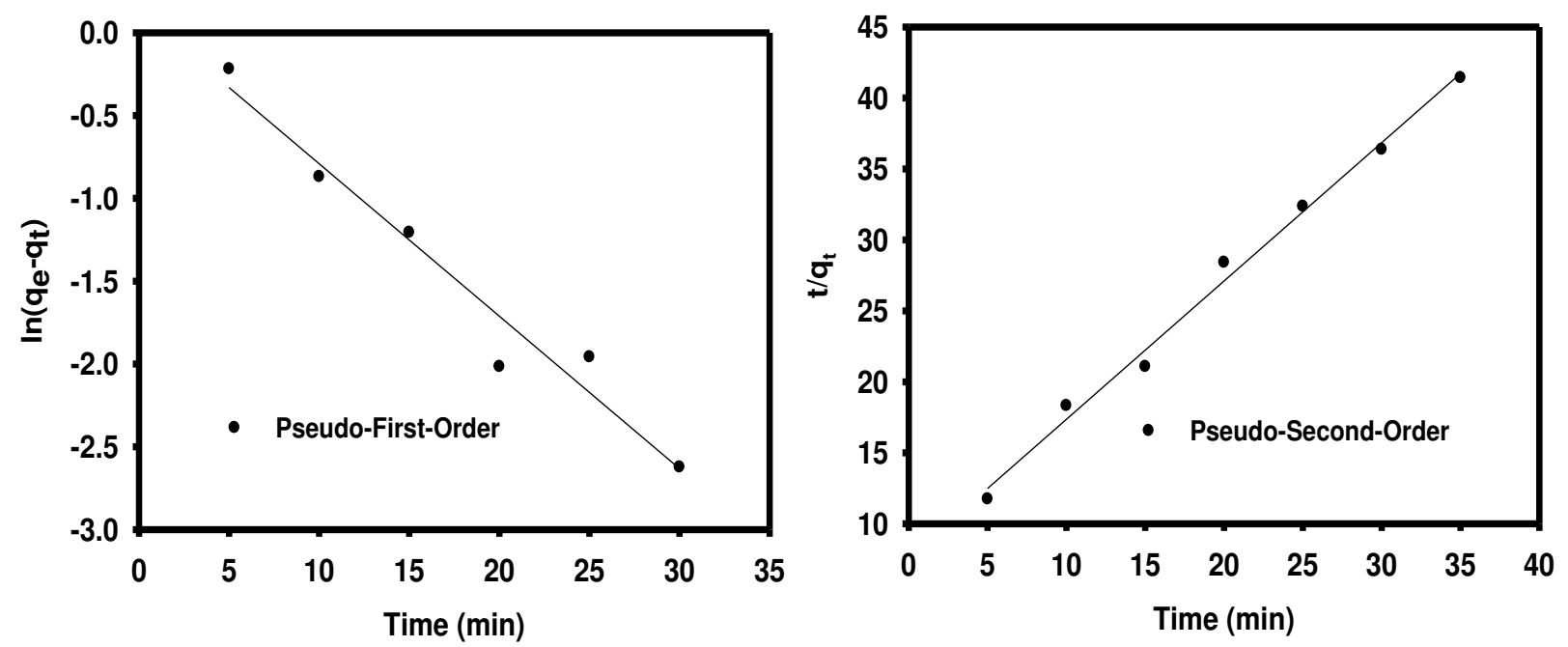

Figure 10: Kinetic models; pseudo-first-order, and pseudo-second-order of catalytic degradation of sandocryl dye by Ca-ALG/Ag nanocomposite beads.

In degradation systems, there is the possibility of intra-particle diffusion being the rate limiting step[22]. Intra-particle diffusion model for the degradation process of sandocryl dye using CaALG/Ag nanocomposite beads as a catalyst is shown in Figure 11 and its kinetics parameter presented in table 1 and it is noticed that the plot nearly had one strait portion which means that the catalytic degradation of sandocryl dye by using Ca-ALG/Ag nanocomposite beads as a catalyst is controlled mainly by the intra particle diffusion step. Also, it is noticed from Figure 11 that the intercept is very near to zero which confirms that the fast degradation in our case is generally controlled by intra-particle diffusion mechanism[23].

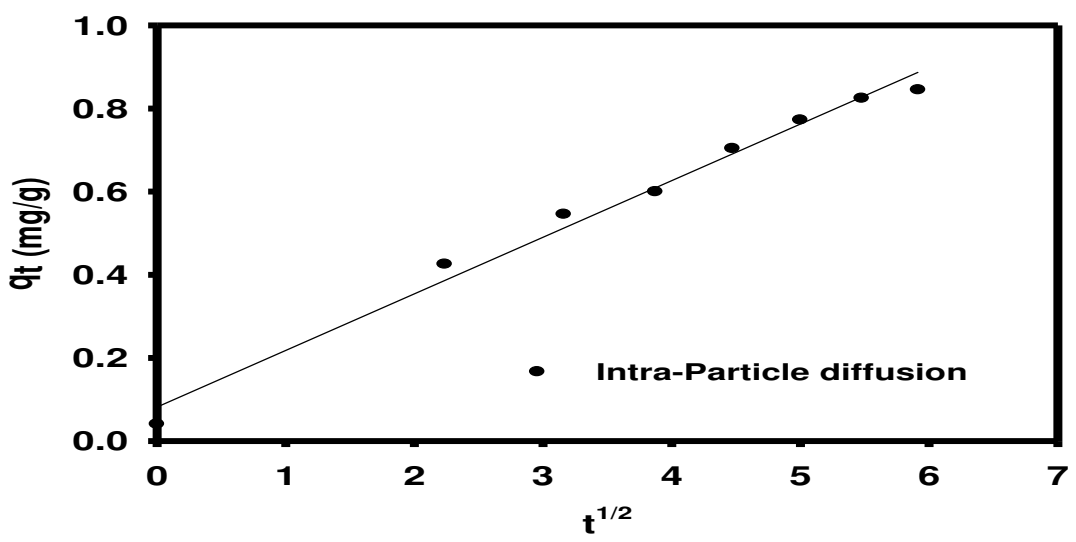

Figure 11: intra-particle diffusion model for the catalytic degradation of sandocryl dye using CaALG/Ag nanocomposite beads 
Table 1: Kinetic and isothermal parameters of the catalytic degradation of sandocryl dye by CaALG/Ag nanocomposite beads.

\begin{tabular}{|c|c|c|c|c|c|c|c|c|}
\hline \multirow[t]{2}{*}{ catalyst } & \multicolumn{4}{|c|}{ Kinetics models } & \multicolumn{4}{|c|}{ Isothermal models } \\
\hline & \multicolumn{2}{|c|}{$\begin{array}{l}\text { Pseudo-First- } \\
\text { Order }\end{array}$} & \multicolumn{2}{|c|}{$\begin{array}{c}\text { Pseudo-Second- } \\
\text { Order }\end{array}$} & \multicolumn{2}{|c|}{$\begin{array}{l}\text { Langmuir } \\
\text { isotherm }\end{array}$} & \multicolumn{2}{|c|}{$\begin{array}{c}\text { Freundlich } \\
\text { Isotherm }\end{array}$} \\
\hline \multirow{5}{*}{ ALG/Ag } & $\mathbf{R}^{2}$ & $\mathbf{K}_{1}$ & $\mathbf{R}^{2}$ & $\mathbf{K}_{2}$ & $\mathbf{R}^{2}$ & $\mathbf{K}_{\mathbf{a}}$ & $\mathbf{R}^{2}$ & $1 / n$ \\
\hline & 0.959 & 0.39 & 0.993 & 22.9 & 0.98 & 0.07 & 0.91 & 0.42 \\
\hline & \multicolumn{4}{|c|}{ Intra-particle diffusion } & & & & \\
\hline & \multicolumn{2}{|c|}{$\mathbf{R}^{2}$} & \multicolumn{2}{|c|}{$\mathbf{K}_{\mathbf{d}}$} & & & & \\
\hline & \multicolumn{2}{|c|}{0.987} & \multicolumn{2}{|c|}{1.4} & & & & \\
\hline
\end{tabular}

\section{Isothermal study}

Two-parameter isotherm models (Langmuir eq. 4, and Freundlich eq. 5)[24] were tested in the fitting of the degradation data of Sandocryl dye by Ca-ALG/Ag nanocomposite beads titanium[25][26]. $K_{a}, K_{F}, K_{T}$ are the Langmuir, Freundlich, and Timken, adsorption equilibrium constants, respectively; $C_{e}$ and $q_{e}$ are the equilibrium concentration, and the adsorption capacity, respectively. The parameter $q_{m}$ represents the maximum monolayer degradation capacity $\left(\mathrm{mg} \mathrm{g}^{-1}\right)$ and $1 / n$ the adsorption intensity, which provides an indication of favorability and capacity of the adsorbent/adsorbate system[27]. The parameter $b$ is related to the adsorption heat; $B D$ gives the mean adsorption free energy $E D\left(\mathrm{~kJ} \mathrm{~mol}^{-1}\right)$. And $R^{2}$ is the corresponding sum of squares error obtained in the fitting experimental data of each model. Figure 12 shows the plotting of the Adsorption isotherm models fitted to experimental degradation of sandocryl dye using CaALG/Ag nanocomposite beads. From the data obtained in Table 1 and monitoring the values of $\mathrm{R}^{2}$ which was 0.98 and 0.91 for Langmuir, and Freundlich isothermal models respectively. It is concluded from these results that the degradation process of sandocryl dye is best fitted by the Langmuir isotherm model. 

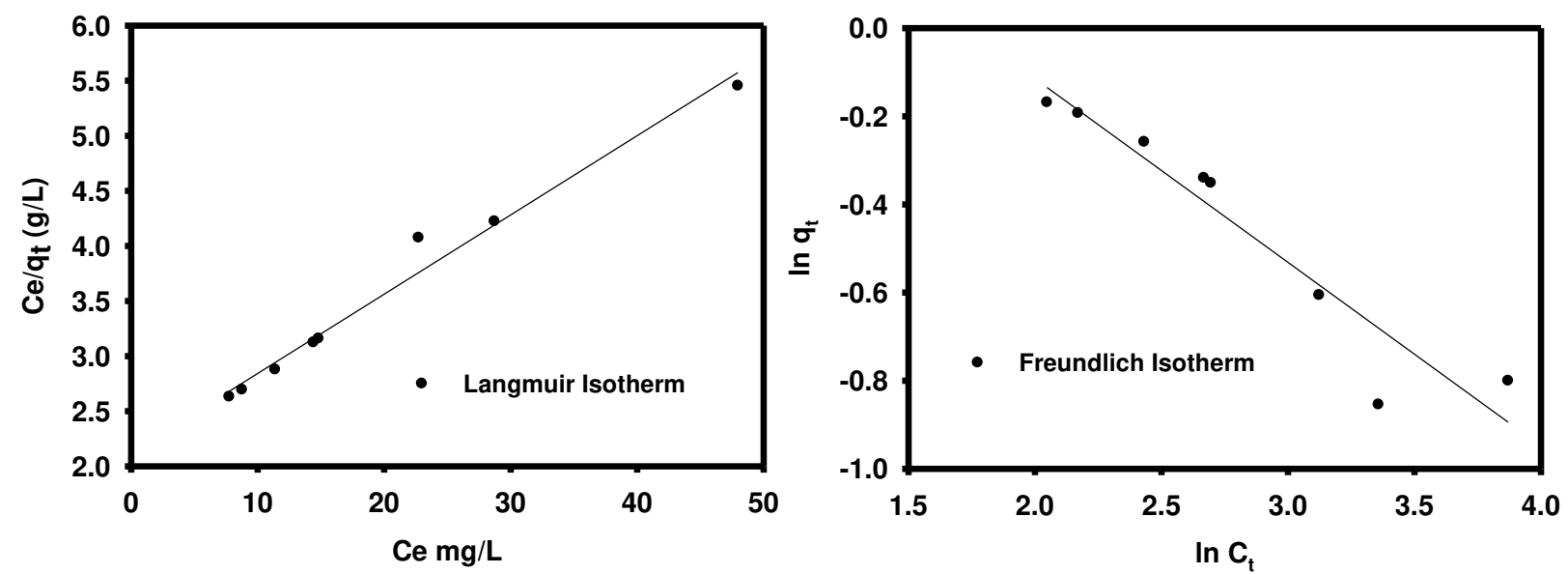

Figure 12: The plotting of the Adsorption isotherm models Langmuir, and Freundlich fitted to experimental degradation of sandocryl dye using Ca-ALG/Ag nanocomposite beads ( $0.1 \mathrm{~g}$ of catalyst, $3 \mathrm{ml} \mathrm{NaBH}_{4}, 1000 \mathrm{mg} / \mathrm{L}$ dye concentration, and $40 \mathrm{ml}$ sample volume).

\section{Conclusions}

Based on our experimental results, the Ca-ALG/Ag nanocomposite beads were successfully synthesized using gamma radiation without using toxic chemicals. The catalytic performance of CaALG/Ag nanocomposite beads for the catalytic degradation of sandocryl dye was tested as a model reaction with $\mathrm{NaBH}_{4}$ as a reducing gent. Catayltic degradation is strongly dependent on different parameter such as time, dose of adsorbent and volume of $\mathrm{NaBH}_{4}$. The catalytic degradation efficiency of sandocryl blue dye was fast in the present condition, 30min and using $0.1 \mathrm{~g}$ of catalyst. Results showed that a pseudo-second-order adsorption kinetic was predominant in the adsorption of sandocryl dye onto the nanocomposite beads. The experimental equilibrated adsorption capacity of the nanocomposite beads agrees with Langmuir isotherm model. The efficiency of $\mathrm{Ca}-\mathrm{ALG} / \mathrm{Ag}$ nanocomposite beads as a promising candidate for the catalysis of organic dyes by $\mathrm{NaBH} 4$ through the electron transfer process is established in the present study.

\section{Acknowledgement}

Taif University Researchers Supporting Project number (TURSP-2020/05), Taif University, Taif, Saudi Arabia.

The authors would like to thank the Deanship of Scientific Research at Prince Sattam bin Abdulaziz University in AlKharj, Saudi Arabia, for their support. 
Also, the authors are very grateful for the great help and facilities provided by the National

Center for Radiation Research and Technology (NCRRT), Cairo, Egypt

The authors declare that there is no conflict of interest

\section{'Data availability'}

The raw/processed data required to reproduce these findings cannot be shared at this time due to technical or time limitations.

\section{References}

1. J. Yang, B. Hou, J. Wang, B. Tian, J. Bi, N. Wang, X. Li, and X. Huang, Nanomaterials 9, (2019).

2. S. Stankic, S. Suman, F. Haque, and J. Vidic, J. Nanobiotechnology 14, 1 (2016).

3. S. Cheriyamundath and S. L. Vavilala, Water Environ. J. 1 (2020).

4. A. Fiorati, A. Bellingeri, C. Punta, I. Corsi, and I. Venditti, Polymers (Basel). 12, (2020).

5. M. Faried, K. Shameli, M. Miyake, A. Hajalilou, A. Zamanian, Z. Zakaria, E. Abouzari-Lotf, H. Hara, N. B. B. Ahmad Khairudin, and M. F. Binti Mad Nordin, J. Nanomater. 2016, (2016).

6. Y. Liu, C. Hou, T. Jiao, J. Song, X. Zhang, R. Xing, J. Zhou, L. Zhang, and Q. Peng, Nanomaterials 8, (2018).

7. F. I. Abou El Fadl and S. M. Ibrahim, J. Nanostructure Chem. 10, 243 (2020).

8. R. Singh and D. Singh, J. Mater. Sci. Mater. Med. 23, 2649 (2012).

9. G. Karthiga Devi, P. Senthil Kumar, and K. Sathish Kumar, Desalin. Water Treat. 57, 27686 (2016).

10. A. H. Shalla, M. A. Bhat, and Z. Yaseen, J. Environ. Chem. Eng. 6, 5938 (2018).

11. J. Chen, Y. Liu, Y. Xiong, D. Wei, J. Peng, S. Mahmud, and H. Liu, Inorganica Chim. Acta 515, (2021).

12. S. Thakur, O. Arotiba, H. M. Marwani, S. Ahmad, A. M. Furuyama Lima, M. De Freitas Lima, O. B. Garrido Assis, A. Raabe, H. C. Amoroso, V. A. De Oliveira Tiera, M. B. De Andrade, M. José Tiera, E. Rodríguez, J. L. Arqués, R. Rodríguez, M. Nuñez, M. Medina, T. L. Talarico, I. A. Casas, T. C. Chung, W. J. Dobrogosz, L. Axelsson, S. E. Lindgren, W. J. Dobrogosz, L. Kerkeni, P. Ruano, L. L. Delgado, S. Picco, L. Villegas, F. Tonelli, M. Merlo, J. Rigau, D. Diaz, M. Masuelli, S. Asadi, S. Eris, S. Azizian, E. A. Bakr, H. G. El-Attar, M. A. Salem, Y. Zhuang, F. Yu, H. Chen, J. Zheng, J. Ma, J. Chen, C. Ray, T. Pal, S. Singh, K. C. Barick, D. Bahadur, S. Maria, A. Francis, V. Thiruvengadam, G. College, E. Salem, R. Krishnan, E. Sustainability, B. Obradovic, J. Stojkovska, Z. Jovanovic, V. Miskovic-Stankovic, U. 
Jinendra, D. Bilehal, B. M. Nagabhushana, K. S. Jithendra Kumara, S. P. Kollur, R. Sabater i Serra, J. Molina-Mateo, C. Torregrosa-Cabanilles, A. Andrio-Balado, J. M. M. Dueñas, Á. Serrano-Aroca, K. Sivaranjan, O. Padmaraj, J. Santhanalakshmi, M. Sathuvan, A. Sathiyaseelan, S. Sagadevan, S. Thakur, B. Sharma, A. Verma, J. Chaudhary, S. Tamulevicius, V. K. Thakur, R. Anbarasan, K. Ponprapakaran, R. Harihara Subramani, R. Baskaran, K. L. Tung, D. Xiao, M. He, Y. Liu, L. Xiong, Q. Zhang, L. Wei, L. Li, and X. Yu, Polym. Bull. 5, 9465 (2020).

13. H. Xiao, R. Wang, L. Dong, Y. Cui, S. Chen, H. Sun, G. Ma, D. Gao, and L. Wang, ACS Omega 4 (2019).

14. F. I. Abou El Fadl, J. Radioanal. Nucl. Chem. 301, 529 (2014).

15. W. Boulaiche, B. Hamdi, and M. Trari, Appl. Water Sci. 9, 1 (2019).

16. M. Kheirabadi, M. Samadi, E. Asadian, Y. Zhou, C. Dong, J. Zhang, and A. Z. Moshfegh, J. Colloid Interface Sci. 537, 66 (2019).

17. B. Singh, A. Kumar, B. Singh, and Rajneesh, Am. J. Drug Deliv. Ther. 5, 1 (2018).

18. M. F. Abou Taleb, F. I. Abou El Fadl, and H. A. Albalwi, J. Inorg. Organomet. Polym. Mater. (2020).

19. L. Andronic, L. Isac, C. Cazan, and A. Enesca, Appl. Sci. 10, 1 (2020).

20. P. Saikia, A. T. Miah, and P. P. Das, J. Chem. Sci. 129, 81 (2017).

21. L. Azeez, A. Lateef, S. A. Adebisi, and A. O. Oyedeji, Appl. Water Sci. 8, 1 (2018).

22. M. A. Khan, R. Govindasamy, A. Ahmad, M. R. Siddiqui, S. A. Alshareef, A. A. H. Hakami, and M. Rafatullah, Polymers (Basel). 13, 1 (2021).

23. S. G. Muntean, M. A. Nistor, E. Muntean, A. Todea, R. Ianoş, and C. Păcurariu, J. Chem. 2018, (2018).

24. R. Wahab, F. Khan, N. K. Kaushik, J. Musarrat, and A. A. Al-Khedhairy, Sci. Rep. 7, 1 (2017).

25. A. Pardo, H. Garcia, P. Ramirez, M. A. Carrillo-Alvarado, K. S. Krishna, N. Dominguez, M. T. Islam, H. Wang, and J. C. Noveron, Environ. Technol. Innov. 11, 321 (2018).

26. S. Xie, Z. Wen, H. Zhan, and M. Jin, Geofluids 2018, (2018).

27. F. Batool, J. Akbar, S. Iqbal, S. Noreen, S. Nasir, and A. Bukhari, (2018). 
Figures

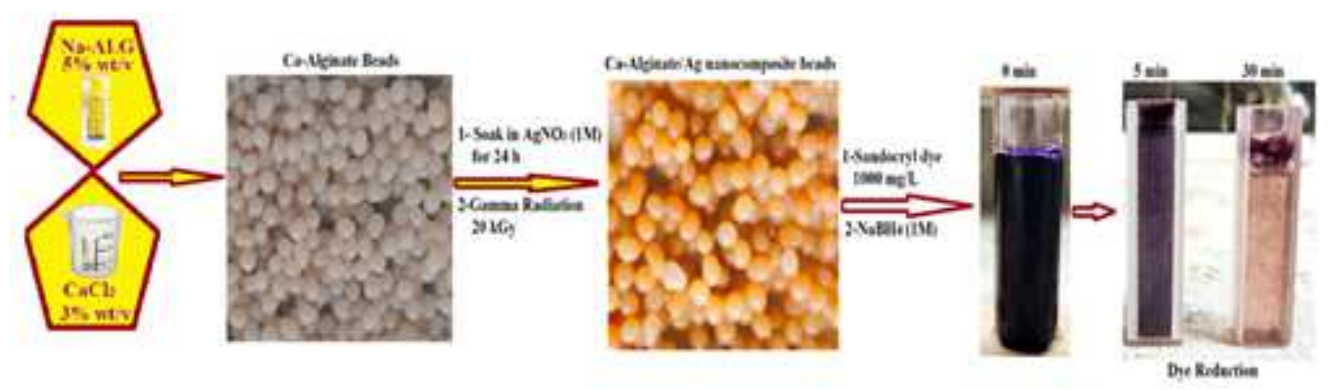

Figure 1

photographic illustration for the preparation and degradation of sandocryl dye using Ca-ALG/Ag nanocomposite beads

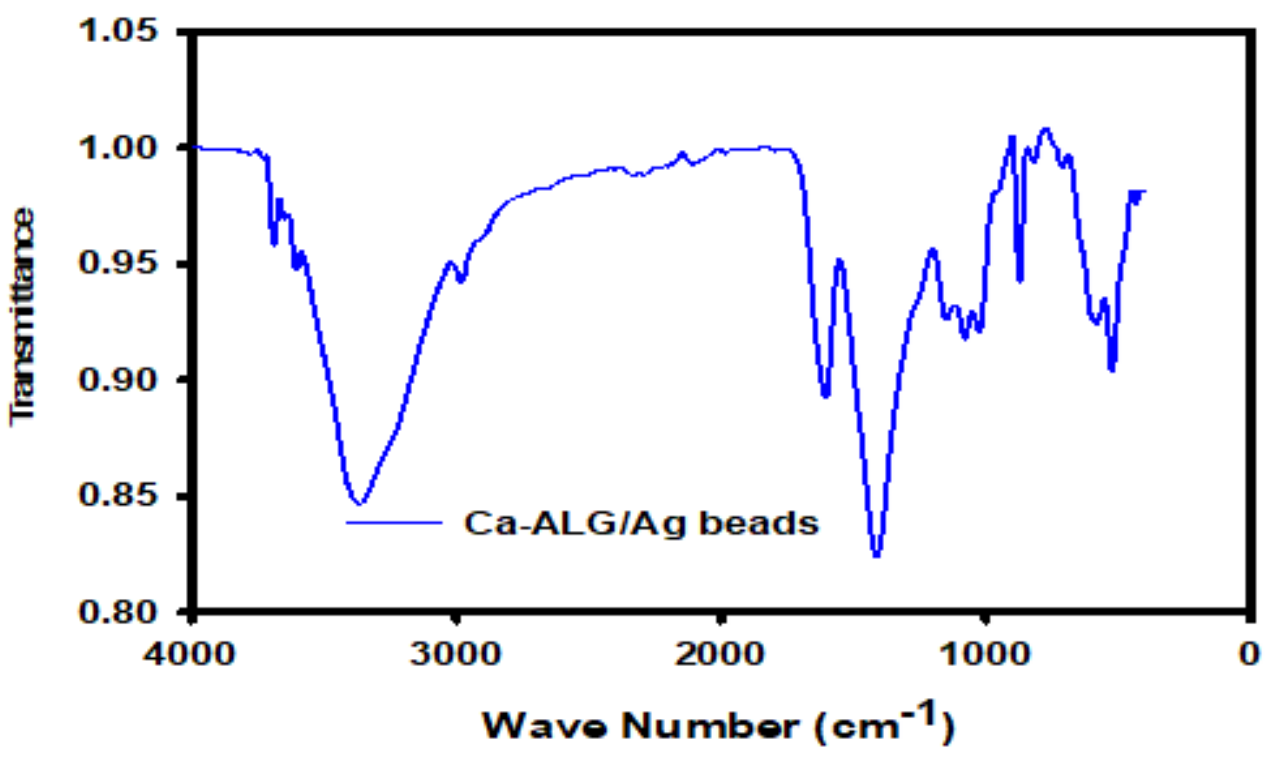

Figure 2

IR spectra of Ca-ALG/Ag nanocomposite beads
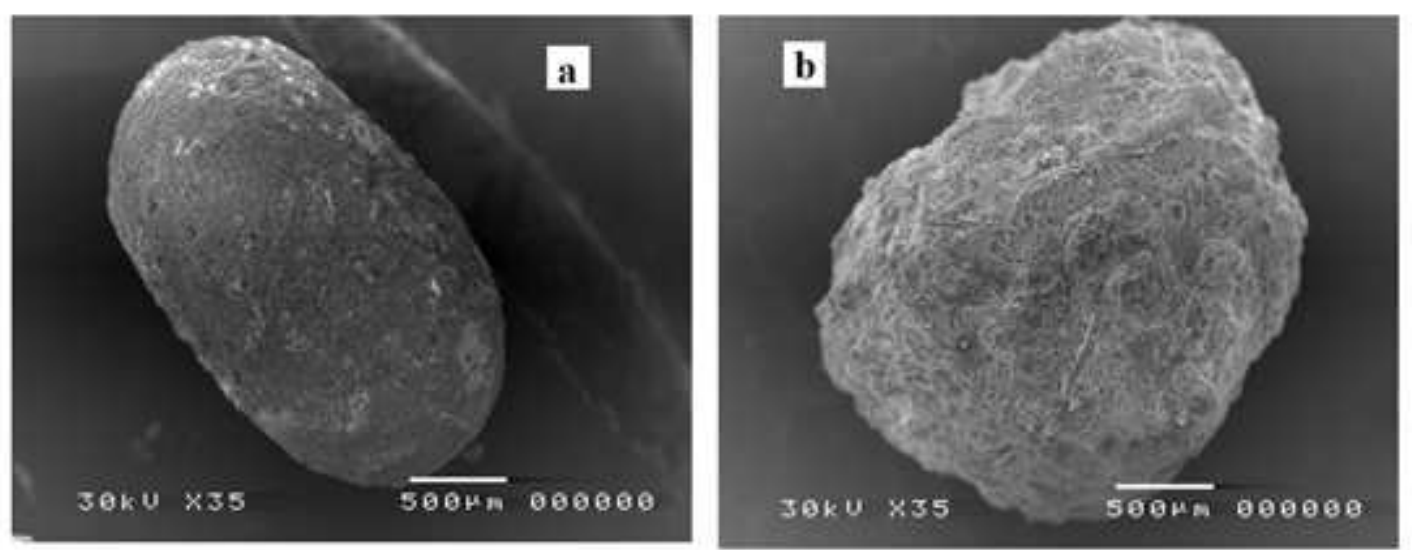
Figure 3

SEM photos of a) Ca-Alginate beads and Ca-ALG/Ag nanocomposite beads

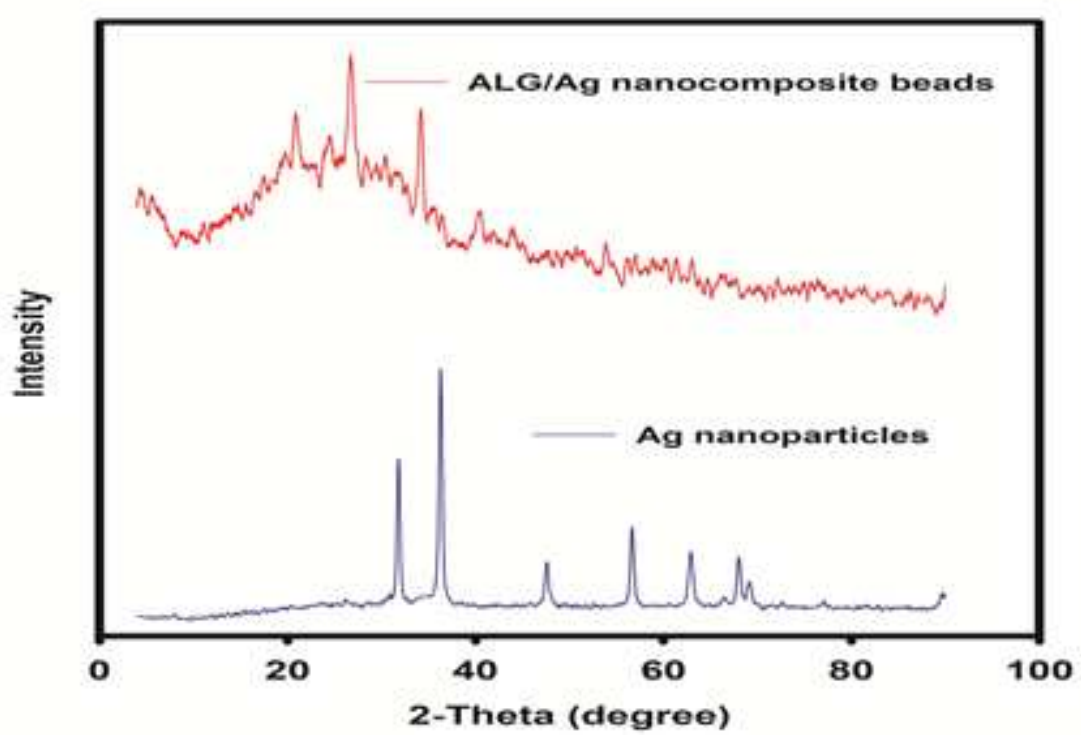

Figure 4

XRD patterns of pure Ag NPs, and Ca-ALG/Ag nanocomposite beads

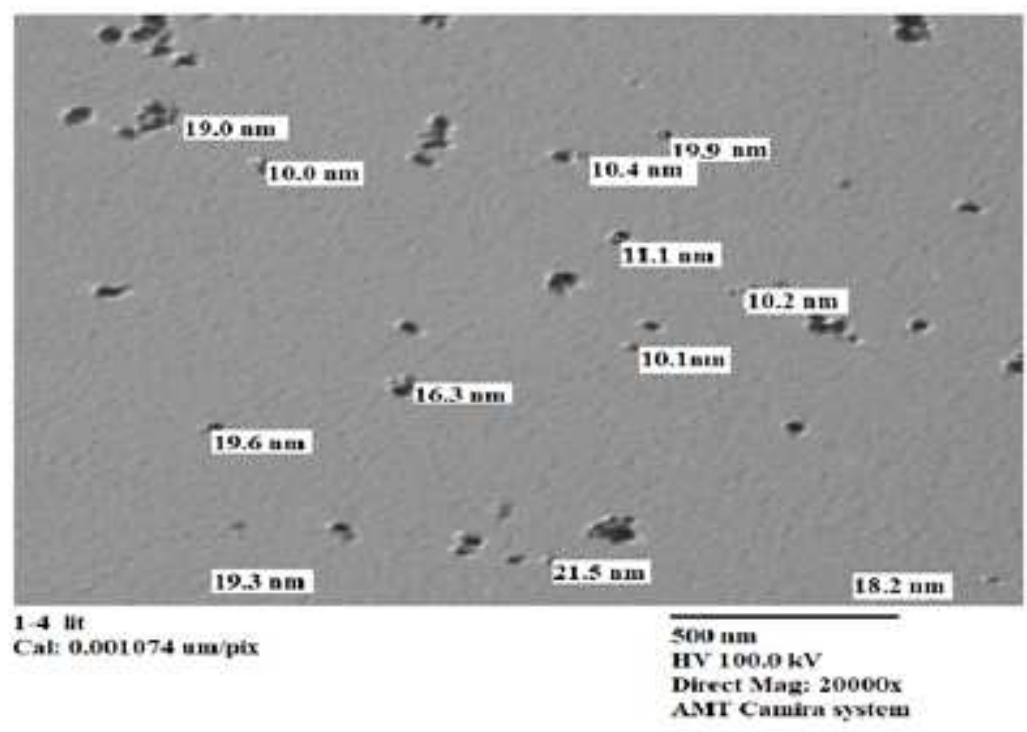

Figure 5

TEM images of Ca-ALG/Ag nanocomposite beads 


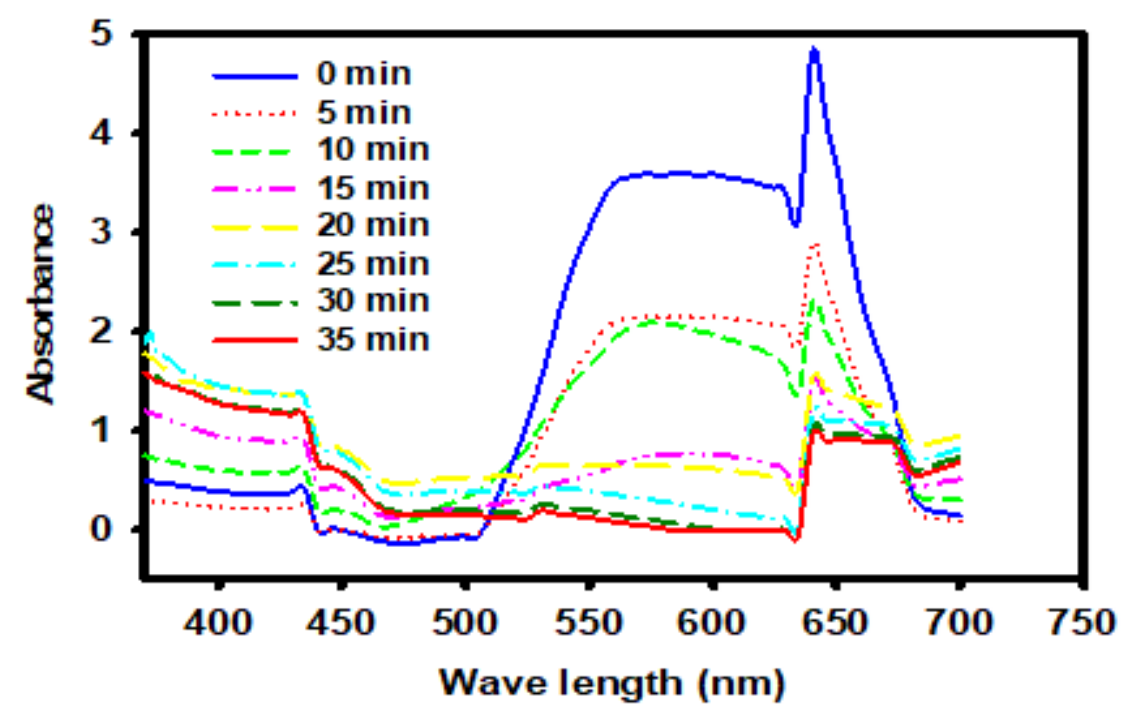

Figure 6

UV-Vis absorption spectra of aqueous sandocryl dye $(40 \mathrm{~mL}, 1000 \mathrm{mg} / \mathrm{L})$ with, $3 \mathrm{~mL}$ of $0.5 \mathrm{M} \mathrm{NaBH} 4$ and $0.1 \mathrm{~g}$ of $\mathrm{Ca}-\mathrm{ALG} / \mathrm{Ag}$ nanocomposite beads
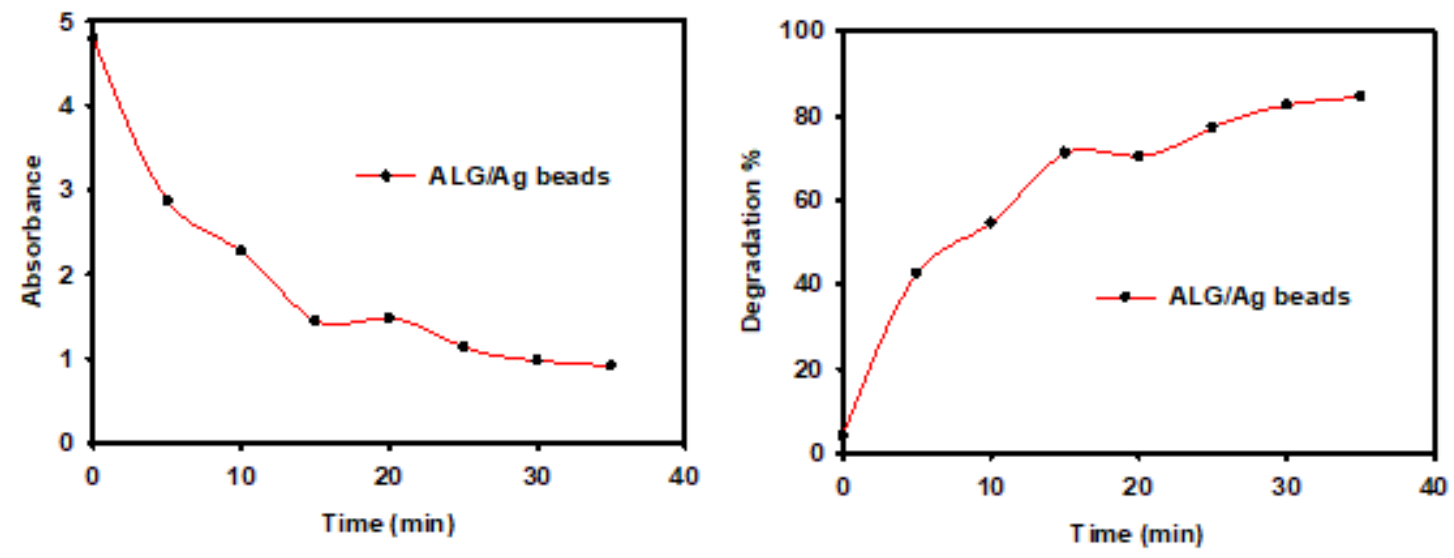

Figure 7

effect of time on the absorbance of sandocryl dye and the degradation \% using Ca-ALG/Ag nanocomposite beads as a catalyst (sample volume $40 \mathrm{ml}$, catalyst dosage $0.1 \mathrm{~g}$, dye concentration $1000 \mathrm{mg} / \mathrm{L}$, and $3 \mathrm{ml}$ of $\mathrm{NaBH} 4$ ) 


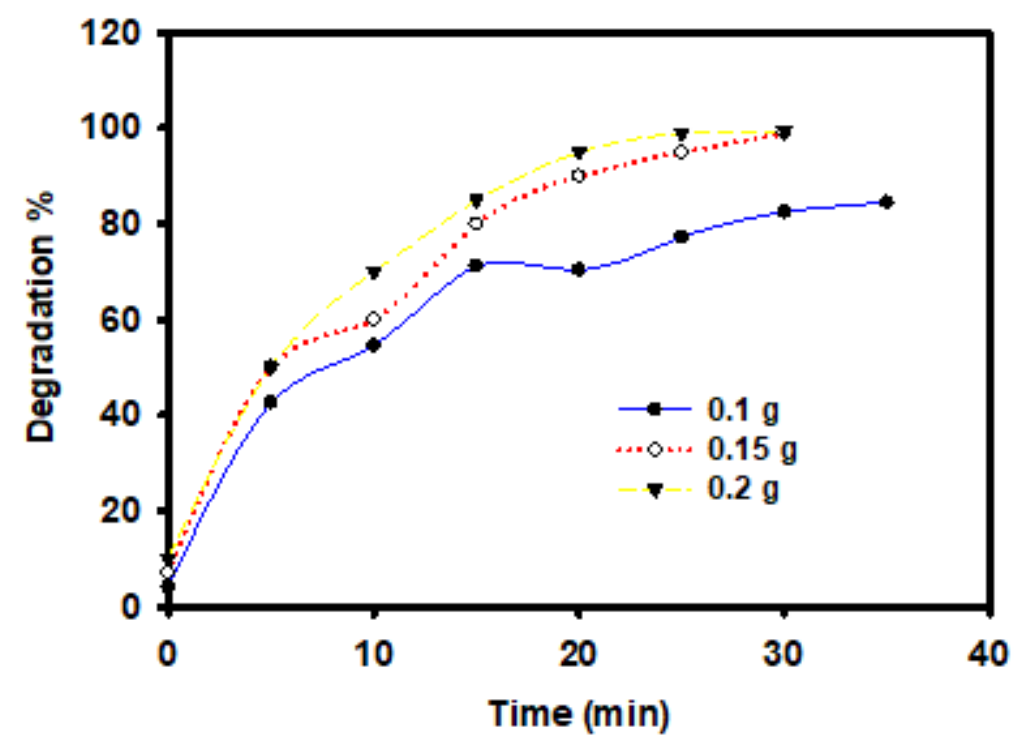

Figure 8

Effect of Ca-ALG/Ag nanocomposite beads dosage on the catalytic degradation of sandocryl dye ( $\mathrm{NaBH} 4$ $3 \mathrm{ml}$, dye concentration $1000 \mathrm{mg} / \mathrm{L}$, and $40 \mathrm{ml}$ sample volume)

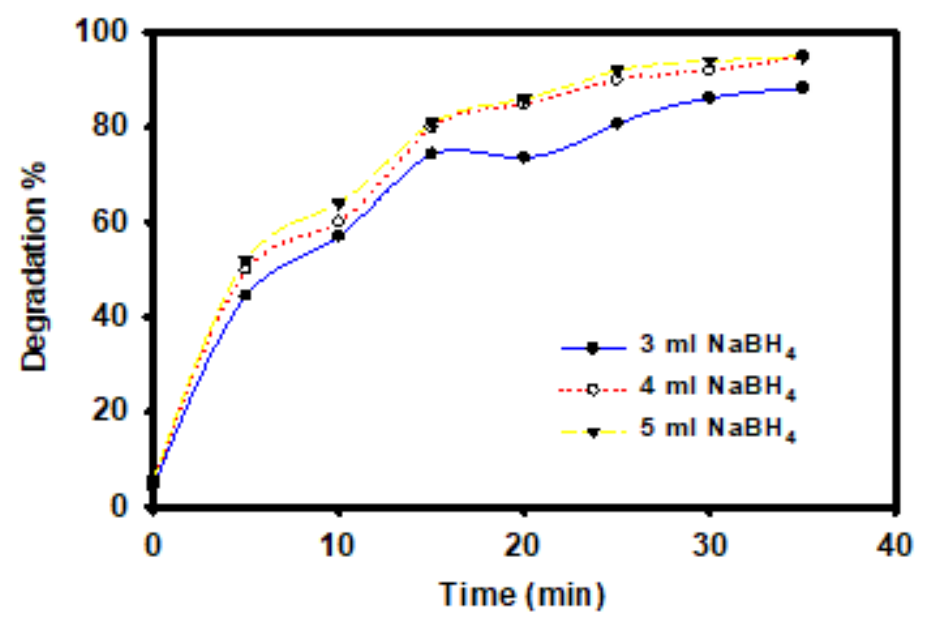

Figure 9

Effect of $\mathrm{NaBH} 4$ volume on the catalytic degradation of sandocryl dye (dye concentration $1000 \mathrm{mg} / \mathrm{L}$, and $40 \mathrm{ml}$ sample volume, catalyst dosage $0.15 \mathrm{~g}$ ) 

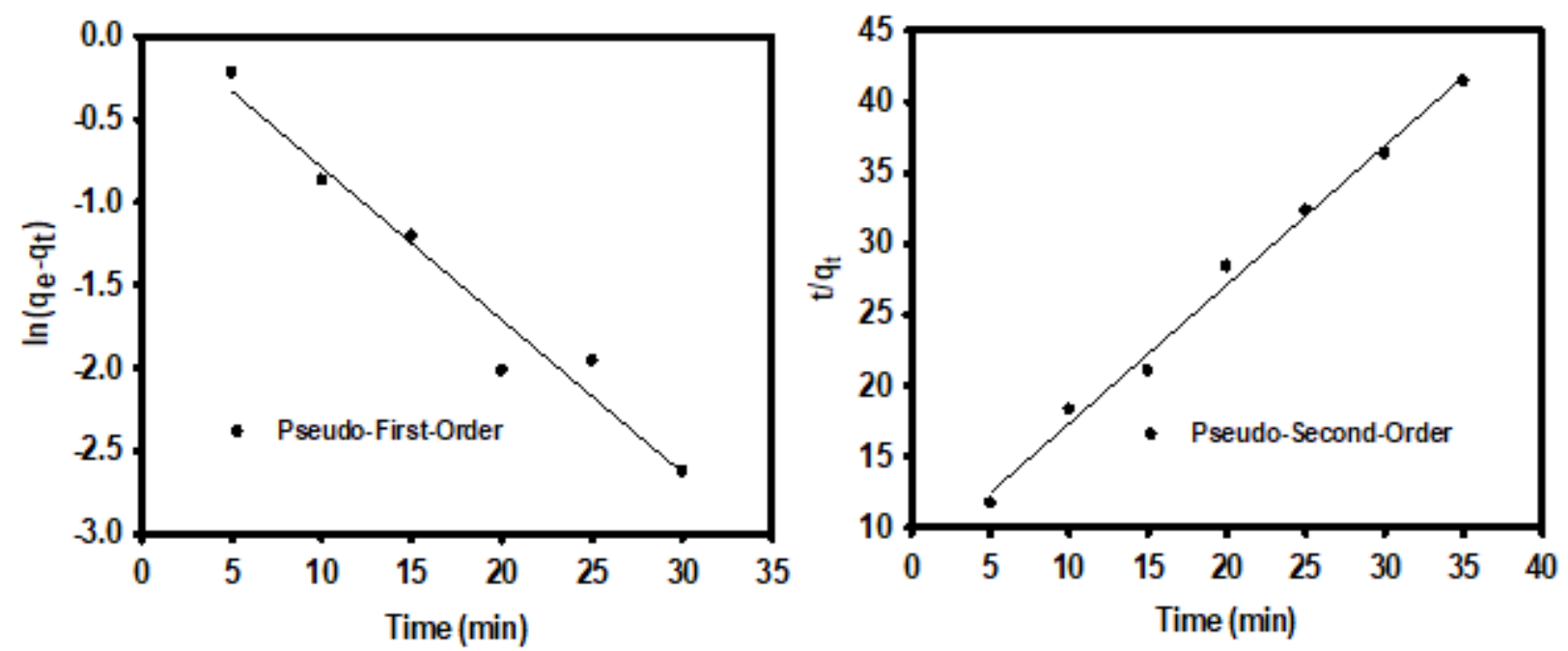

Figure 10

Kinetic models; pseudo-first-order, and pseudo-second-order of catalytic degradation of sandocryl dye by Ca-ALG/Ag nanocomposite beads.

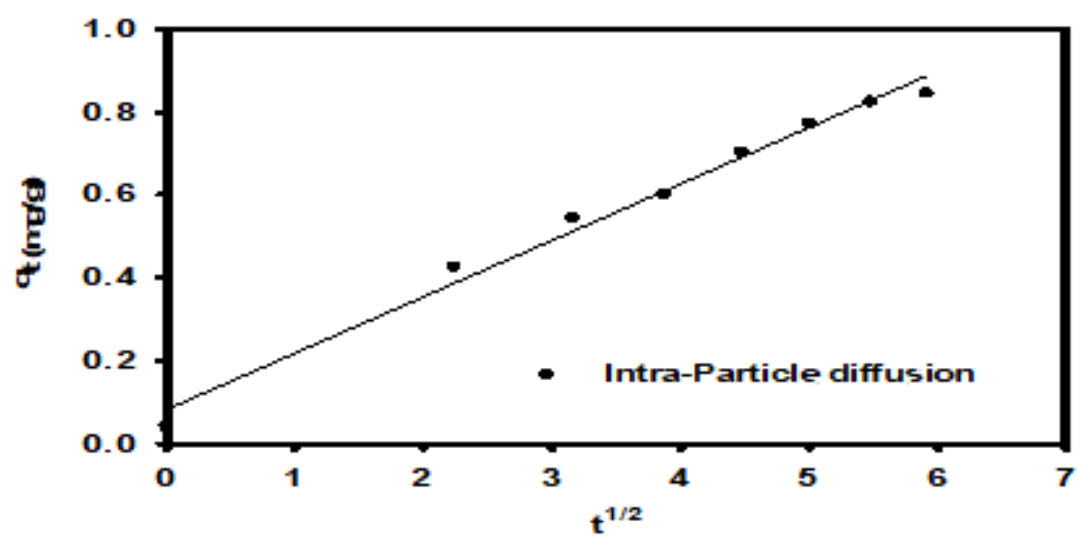

\section{Figure 11}

intra-particle diffusion model for the catalytic degradation of sandocryl dye using Ca-ALG/Ag nanocomposite beads 

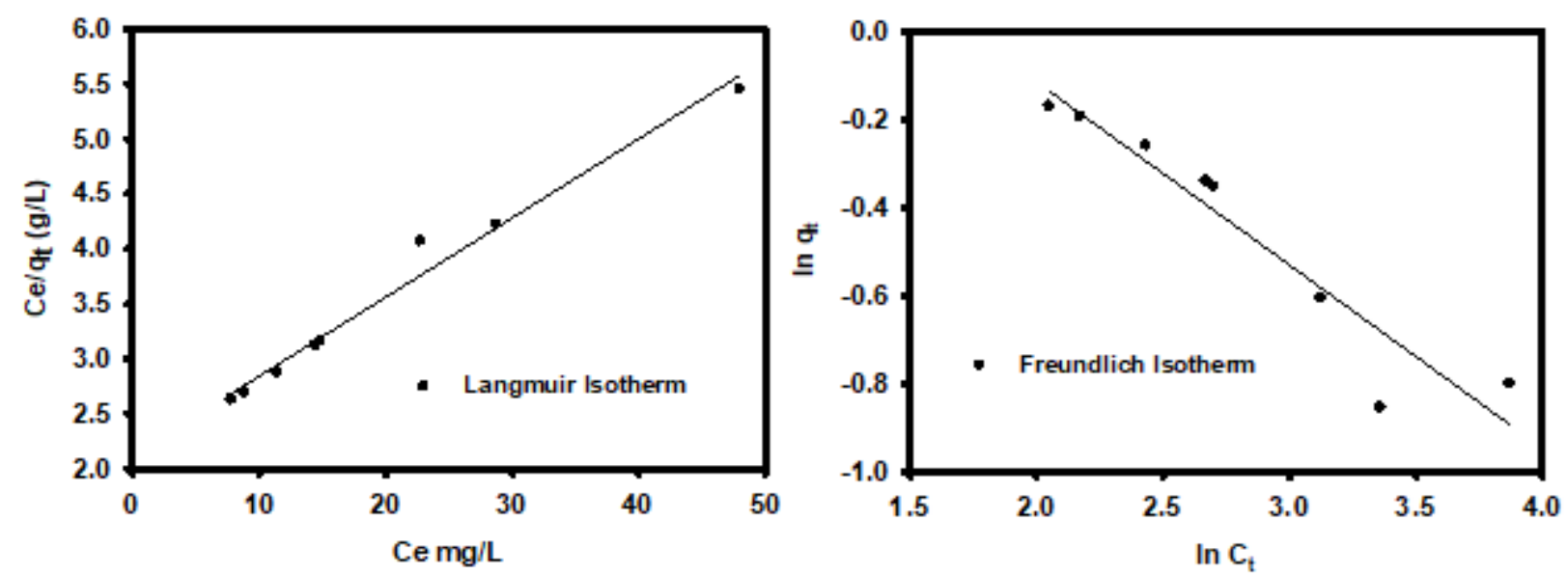

Figure 12

The plotting of the Adsorption isotherm models Langmuir, and Freundlich fitted to experimental degradation of sandocryl dye using Ca-ALG/Ag nanocomposite beads $(0.1 \mathrm{~g}$ of catalyst, $3 \mathrm{ml} \mathrm{NaBH} 4$, $1000 \mathrm{mg} / \mathrm{L}$ dye concentration, and $40 \mathrm{ml}$ sample volume). 